\title{
The competitiveness of saudi dates in global markets and its effect on future exports
}

\author{
Mohamad Alnafissa ${ }^{1, *}$, Adel Ghanem ${ }^{2}$, Yosef Alamri ${ }^{3}$ and Fuad Alagsam ${ }^{4}$ \\ Department of Agricultural Economics, College of Food and Agricultural Sciences; King Saud University, P.O. Box 2460 \\ Riyadh 11451, Saudi Arabia \\ *Corresponding author's e-mail: malnafissa@ksu.edu.sa
}

\begin{abstract}
The production of dates has been increasing in Saudi Arabia during 1970-2019. However, this growth has not been accompanied by a proportionate increase in exports to global markets, with only $5.5 \%$ on average of the produced dates being destined for export in the same period (1970-2019). This study compares the competitiveness of Saudi date exports to several overseas markets and its effect on future exports. Our study hypothesizes that Saudi Arabia has the competitiveness of Saudi dates exports comparing others and this competitiveness could have a significant effect on Saudi's dates exports. We test such a hypothesis by using the market share data and the RCA for countries that were the top exporters of dates in 2019.The Partial Adjustment Model is employed to explore the impact of the competitiveness of Saudi dates on future exports. The results showed that Saudi Arabia as well as other major date-exporting countries (Iran, Iraq, Israel, Pakistan, Tunisia, and the UAE) have high competitiveness in the global market. By division of markets by groups of countries, Saudi Arabia has a comparative advantage over at least four countries among the top six exporters in three markets (Africa, Asia, and the OIC), while Saudi dates are less competitive in the American and European markets, where it never held a dominant position. The general trend equation indicates that the decline in the competitiveness of Saudi dates will continue during 2021-2025.
\end{abstract}

Keywords: Competitiveness, dates market, revealed comparative advantage, partial adjustment model.

\section{INTRODUCTION}

Dates are considered among the main agricultural products in several countries, especially in Islamic countries, because of their economic importance and the high demand for them in Islamic culture. In addition, there has been an increase in the global demand for dates, and the cultivation of date palms is expanding in various countries. However, historically, date production has been closely linked to the Arabian Peninsula, where the production and consumption of dates is associated with the culture of the inhabitants. Therefore, most Saudi cities and villages have palm farms. Of late, there has been increasing interest in date cultivation, with government support to farmers leading to a further growth in the overall level of date production in the Kingdom. The production of dates has increased from about 240,000 tons in 1970, representing approximately $8 \%$ of world production, to approximately 528,000 tons in 1990 , accounting for $15 \%$ of global production (Faostat, 2021; International Trade Centre, 2021). The cultivation of dates continues to increase, rising to more than $1,095,000$ tons in 2013, representing $14.5 \%$ of the world's production (Faostat, 2021).In 2016, the production of dates in Saudi Arabia was (1.54 million tons) ranked second in the world, after Egypt accountedfor $17 \%$ of global production volumes(Fig. 1). In the last ten years, Saudi dates domestic production and domestic consumption increased by $64 \%$ and $68 \%$; respectively. However, this growth in date production in Saudi Arabia was not accompanied by a proportionate increase in exports. The percentage of Saudi date exports from domestic production during the period (1970-2019) ranged from 2.7\% to $12 \%$. Meanwhile, there is growing interest in Saudi Arabia to increase date exports, with $20 \%$ of all domestically-produced dates in 2014 being exported.

This study compares the competitiveness of Saudi date exports in overseas markets and its effect on future exports. A competitiveness analysis for specific products in the world market involves analyzing countries that have a comparative advantage over others. This analysis is helpful for the laggard countries to improve the market share for their products. In addition, a country with a less relative advantage in certain areas may have a comparative advantage in others. Competitiveness analyses for agricultural products in the global export market is popular in the literature; for example,

Alnafissa1, M., A. Ghanem, Y. Alamri and F. Alagsam. 2021.The competitiveness of Saudi dates in global markets and its effect on future exports. Pak. J. Agri. Sci. 58:1115-1122

[Received 17 Jun 2020; Accepted 19 Jun 2021; Published (online) 21 Sep. 2021] 
studies have analyzed the competitiveness of Egyptian fruits and vegetables in the EU market (Helmy, 2010; Torayeh, 2013); Pakistani agricultural products (rice, fish, vegetables, fruits, dates, and meat) (Akhtar et al., 2009; Rizwan-ulHassan, 2013 and Kousar et al., 2019); Indonesia's cocoa beans (Rifin, 2013); and the Chinese apple (Ahmed et al., 2011) in the global market. Through these studies, researchers use several methodologies to measure competitiveness such as revealed comparative advantage index, revealed symmetric comparative advantage index, and relative export advantage index.

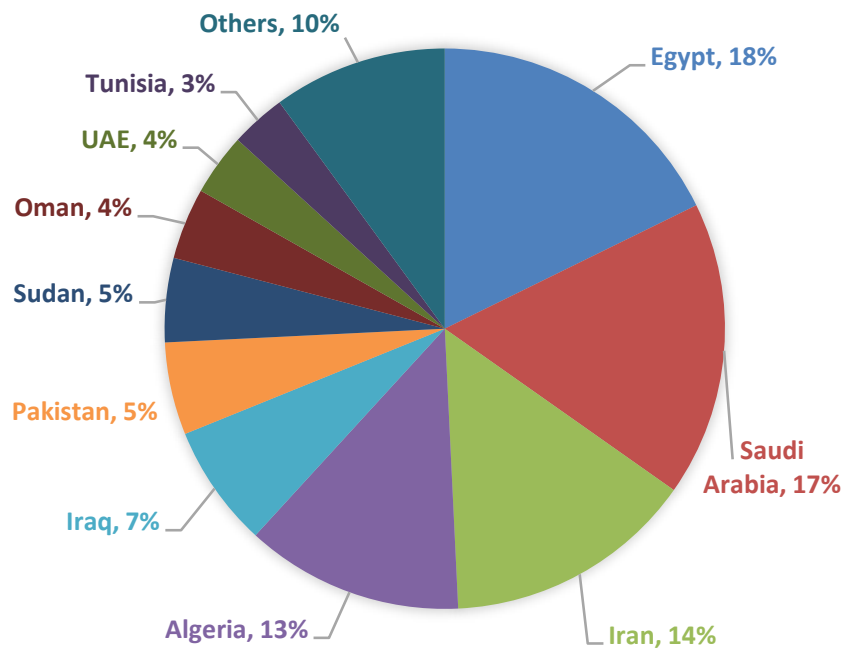

Source: Faostat, 2019.

Figure 1. Production of Dates by Country in 2016 (as a \% of world's production).

Given the large body of research regarding the competitiveness of agricultural products in the global market, it is still essential to understand the competitiveness of the Saudi date elsewhere. We contribute to the existing literature by measuring the competitiveness of Saudi dates relative to other major exporters in selected global markets, including Africa, Asia, America, Europe, and the aggregate market for members of the Organization of Islamic Countries (OIC). The results of our analysis will foster a better understanding of the competitiveness of Saudi date in the international market to help exporters set their marketing strategy and government design effective policy to promote date exporters.

Initially, the study identified major global players in the export of dates by measuring their market share. Then, an analysis was conducted on the competition between these countries over the years. Consequently, we could compare the competitiveness of dates originating from Saudi Arabia with those produced by its competitors. Finally, the study explored the impact of the competitiveness of Saudi dates on future exports.

The rest of this paper includes four sections. The first section introduces the materials and methods our analysis incorporates. The second represents the results, and the last two sections, respectively, provide the conclusion and recommendations.

\section{MATERIALS AND METHODS}

The competitiveness of Saudi dates exports was analyzed using the market share (MS) data and the revealed comparative advantage (RCA) for countries that were the top exporters of dates in 2019. Then, the RCA index for Saudi Arabia was used to determine its effect on future Saudi date exports.

Market share analysis: The market share of date exports for a country is the proportion of the total value of its date exports to the total export value of the same product in the world during the same period. Therefore, the market share is Then, the following equation (Han et al., 2009):

$$
M S_{i}=\frac{T E_{i}}{T E_{w}}
$$

where, $M S_{i}$ is the market share of date exports in the world market for a country $i$; $T E_{i}$ is the total export value of dates for a country $i ; T E_{w}$ is the total world export value of dates. It must be noted that price and non-price (quality and taste) factors could affect the market share of a country (Benkovskis and Wörz, 2018), which in turn influenced the size of production and the domestic consumption of the product. The change in market share for a country over a certain period of over a change in the competitive position of that country in the global product market.

Revealed comparative advantage indices: The RCA index is used to measure the relative importance of date export for the main players in the global market. RCA was calculated for several years in three different ways. First, the calculation of $\mathrm{RCA}_{1}$ among countries that are major exporters of dates in the world, with respect to the total export value of dates across the globe in the period t (equation 2) (Balassa, 1965; Brasili et al., 2000 and Han et al., 2009). The value of equation 2 reflects the proportion of date exports in the aggregate exports of agricultural products of a country to the same proportion in the world market.

$$
R C A_{1 i t}=\frac{D E_{i t} / \Sigma A g E_{i t}}{\Sigma D E_{w t} / \Sigma A g E_{w t}}
$$

Where, $R C A_{1 i t}$ is the relative export advantage index for dates for country $i$ versus all other exporting countries in period $t$ $D E_{i t}$ is the total value of date exports for country $i$ in period $t ; \Sigma A g E_{i t}$ is the total value of exports of agricultural products for country $i$ in period $t ; \Sigma D E_{w t}$ is the total value of exports of dates for the world in period $t ; \Sigma A g E_{w t}$ is the total value of exports of agricultural products for the world in period $t$.

Second, $\mathrm{RCA}_{2}$ is used to evaluate the competitive position of Saudi date exports in selected markets (world, Africa, America, Asia, Europe, and the OIC market) relative to rival countries (equation 3) (Suntharalingam et al., 2011). 
Therefore, the value of equation 3 will reflect the proportion of date exports in the aggregate export of agricultural products for a country to the same proportion in other countries in specific markets.

$$
R C A_{2 m}=\frac{D E_{\text {imt }} / \Sigma A g E_{\text {imt }}}{D E_{j m t} / \Sigma A g E_{j m t}}
$$

where the definition of the variables were similar to equation 2 , except, $\mathrm{m}$ denotes the selected market and $\mathrm{j}$ represent the rival country.

The values of $R C A$ in equation 2 and 3 range between 0 and $+\infty$. A country has a comparative advantage position in the world market as in equation (2) or compared to a competing country in a specific market if $R C A>1$, while it has a comparative disadvantage if $R C A<1$.

Partial Adjustment Model: Estimating the partial adjustment model is a long-term dynamic model that can be formulated as follows:

$$
Y_{t}^{*}=a+b_{1} P_{x t}^{*}+b_{2} X_{n t}+u_{t}
$$

Where, $Y_{t}^{*}$ represents the target level of the quantity of Saudi exports of dates, $P_{x t}^{*}$ average export price, and $X_{n t}$ represents the exogenous variables during the study period $t$.

We cannot estimate the optimal choice of the export quantity $Y^{*}$ and followed a method of partial adjustments, we assume

which means:

$$
Y_{t}-Y_{t-1}=\gamma\left(Y_{t}^{*}-Y_{t-1}\right)
$$

$$
Y_{t}=\gamma Y_{t}^{*}+(1-\gamma) Y_{t-1}
$$

Since the supplier changes the export quantity according to the expected prices, it can be calculated as:

$$
P_{x t}^{*}=\delta P_{x t-1}+(1-\delta) P_{x t-1}^{*}
$$

This means that the actual and previous expected prices could play an effective role in changing the decision of the supplier. From equations 4 and 7 , we could conclude that:

$$
Y_{t}=\gamma a+\gamma b_{1} P_{x t}^{*}+\gamma b_{2} X_{n t}+(1-\gamma) Y_{t-1}+\gamma u_{t}
$$

Then, by using Koyck transformation, we first substitute equation 7 into 8 . Subsequently, by lagging and multiplying by $(1-\delta)$ in equation 8 , we can conclude:

$$
\begin{aligned}
Y_{t}=\gamma \delta a+\gamma \delta b_{1} & P_{x t-1}+\gamma b_{2} X_{n t}-(1-\delta) \gamma b_{2} X_{n t-1} \\
& +(1-\delta) Y_{t-1}+(1-\gamma) Y_{t-1} \\
& -(1-\gamma)(1-\delta) Y_{t-2}+\gamma u_{t} \\
& -(1-\delta) \gamma u_{t}
\end{aligned}
$$

Thus, we can rewrite our model as follows:

$$
\begin{gathered}
Y_{t}=\vartheta_{0}+\vartheta_{1} P_{x t-1}+\vartheta_{2} X_{n t}+\vartheta_{3} X_{n t-1}+\vartheta_{4} Y_{t-1}+\vartheta_{5} Y_{t-2} \\
+\varepsilon_{t}(10)
\end{gathered}
$$

where: $\vartheta_{0}=\gamma \delta a, \vartheta_{1}=\gamma \delta b_{1}, \vartheta_{2}=\gamma b_{2}, \vartheta_{3}=-(1-\delta) \gamma b_{2}$, $\vartheta_{4}=(1-\delta)+(1-\gamma)$

$\vartheta_{5}=-(1-\gamma)(1-\delta)$, and $\varepsilon_{t}=\gamma u_{t}-(1-\delta) \gamma u_{t}$

Then we can calculate the long and short run elasticities for these variables.

$\lambda$ represents the modification coefficient, with values between 0 and 1 . A value of $\lambda$ close to 0 indicates that a small fraction of the imbalance between the actual and equilibrium situation is adjusted within a single time period, while a value close to 1 indicates that a large part of the gap between the actual situation and its desired counterpart is covered within the time period. Therefore, the value of $\lambda$ determines the speed of adjustment, while the average delay period or adjustment lag is equal to $(1-\lambda) / \lambda$.

Model specification:

Multi-stage regression analysis in estimating the Partial Adjustment Model is a short-term dynamic model as following (William, 2003):

$$
\begin{gathered}
Y_{t}=a \lambda+(1-\lambda) Y_{t-1}+b_{1} \lambda X_{1}+b_{2} \lambda X_{2}+b_{3} \lambda X_{3}+b_{4} \lambda X_{4} \\
+b_{5} \lambda X_{5}+b_{6} \lambda X_{6}+e_{t}
\end{gathered}
$$

The future volumes of Saudi date exports $Y_{t}$ is determined in this study by a set of economic factors such as: (1) the quantity of Saudi exports of dates in the previous year $Y_{t-1}$, (2) the domestic production of dates $X_{1 t}$, (3) the amount of domestic consumption $X_{2 t}$, (4) the average export price in year $X_{3 t},(5)$ the comparative advantage of date exports with respect to the export of other agricultural products $X_{4 t}$. The study follows a stepwise multiple regression analysis for the variables that affect the quantity of Saudi date exports during 1971-2019 in linear and double logarithmic functions.

\section{RESULTS AND DISCUSSION}

Global market shares of date exporters: The market share for date exporters in this section includes the market share in the global market for major exporters. The research relies on data from 2019for the top exporters of dates in the world (FAOSTAT, 2021, and International Trade Centre, 2021). According to the results in Table 1, the Iraq was are the largest exporter, with a $39 \%$ global market share in 2019, followed by United Arab Emirates (11.6\%), Saudi Arabia (9.9\%), Iran $(8.8 \%)$, Israel (7.5\%), Tunisia (6.2\%), and Pakistan (5.2\%). The analysis of the market shares in 2016 in comparison with the market share for the same countries in various years $(1980,1990,2000$, and 2010) is available in the same table. The main point in the historical analysis of market shares is that the concentration in the export of dates was less in 2010 and 2019than in the other years of the study. As can be seen in Table 1, Iraq had the largest share in the global date export market in 1980 (76.72\%),1990 (45.68\%), and 2019 (39\%), while the United Arab Emirates alone accounted for $41 \%$ of global dates exports in 2000. Most other countries such as Iran, Israel, Pakistan, Tunisia, and the United Arab Emirates held a small proportion of the market share in the export market in 1980 (less than 2\%), but they increased their share over time. In the case of Saudi Arabia, its market share in the global market was higher than that of other top dates exporters in 2019 , by $11.6 \%$.

In terms of the effect of production size on market share, the study calculates the percentage of domestic production of dates relative to global production for top producers between 1980 and 2019(Table 2). Countries are selected in this table based on the production size of dates in 2019. Therefore, Egypt, Iran, Algeria, Saudi Arabia, the United Arab Emirates, 
Iraq, and Pakistan are included in Table 2. It is evident that some of the top countries based on the size of date production were not among the countries with top exports, such as Egypt and Algeria. Conversely, there are some leading date exporters with modest production levels, such as Israel and Tunisia. Meanwhile, in some other countries such as Iran, Saudi Arabia, Pakistan, and Iraq, date exports accounted for only a small portion of their overall production during the study period (1980-2019). In other cases, such as the United Arab Emirates, the global market shares for date exports exceeded the percentage of domestic production relative to global production during the same period, which could be reflected in the active date trade, both in imports and exports.

Table 1. Global Market Share for the Top Exporters of Dates in 1980-2019.

\begin{tabular}{lrrrrr}
\hline Country & $\mathbf{1 9 8 0}$ & $\mathbf{1 9 9 0}$ & $\mathbf{2 0 0 0}$ & $\mathbf{2 0 1 0}$ & $\mathbf{2 0 1 9}$ \\
\hline Iran & 0.20 & 11.06 & 19.89 & 16.01 & 8.82 \\
Iraq & 76.72 & 45.68 & 5.53 & 19.01 & 39.04 \\
Israel & 0.63 & 1.03 & 0.25 & 1.90 & 7.54 \\
Pakistan & 0.07 & 6.70 & 14.51 & 18.25 & 5.19 \\
Saudi Arabia & 4.27 & 4.88 & 5.21 & 11 & 9.93 \\
Tunisia & 1.81 & 4.34 & 4.13 & 12.64 & 6.20 \\
United Arab & 0.91 & 13.71 & 40.96 & 7.51 & 11.59 \\
Emirates & \multicolumn{7}{l}{12.61} & 9.51 & 13.67 & 11.70 \\
Others & 15.40 & 12.61 & & & \\
Source: calculated by author. & & & &
\end{tabular}

Table 2. The Percentage of Domestic Production of Dates to the Global Production for the Top Producers in 1980-2019

\begin{tabular}{lrrrrr}
\hline Country & $\mathbf{1 9 8 0}$ & $\mathbf{1 9 9 0}$ & $\mathbf{2 0 0 0}$ & $\mathbf{2 0 1 0}$ & $\mathbf{2 0 1 9}$ \\
\hline Algeria & 7.55 & 6.00 & 5.68 & 8.57 & 12.52 \\
Egypt & 16.77 & 15.8 & 15.63 & 17.98 & 17.67 \\
Iran & 9.40 & 15.05 & 12.48 & 13.38 & 14.41 \\
Iraq & 22.45 & 15.88 & 14.47 & 7.54 & 7.04 \\
Pakistan & 7.30 & 8.37 & 9.51 & 6.96 & 5.32 \\
Saudi Arabia & 12.88 & 15.39 & 11.41 & 13.18 & 16.97 \\
United Arab & 1.92 & 4.12 & 11.76 & 10.97 & 3.56 \\
Emirates & & & & & \\
Others & 21.74 & 19.39 & 19.06 & 21.43 & 22.50 \\
Source: & & & & &
\end{tabular}

Source: calculated by author.

The revealed comparative advantages for Saudi dates in global markets: Two methods are used to analyze the competitiveness of Saudi dates in the global market in this section. First, we analyzed the RCA of date exports compared to total exports of agricultural products for the major dateexporting countries to gauge whether date total exports be an advantage over exports of other agricultural products. Second, we investigated the RCA for Saudi dates relative to other countries in several world markets.
The competitiveness of date other countries the export of other agricultural products for major date-exporting nations in the global market.

The top date-exporting countries are selected in this study based on nations that had a high market share in the global market in 2019, including Iran, Iraq, Israel, Pakistan, Saudi Arabia, Tunisia, and the United Arab Emirates. These countries represented $88 \%$ of global date exports during that year (Table 1). The RCA indices for top date exporters in the world between 1980 and 2019 are illustrated in Table 3. In general, RCA indices are above 1 for all the selected countries in this analysis, indicating that they have a comparative advantage in date exports and that their share of date exports over exports of other agricultural products exceeds the average share of exports of agricultural products across the world during the study period (1980-2019), which means that they have high competitiveness in the world market in terms of date exports, except for Pakistan in 1980 (RCA = 0.24). Iraq has the highest relative share of date exports relative to its exports of agricultural products when compared to the same percentage at the global level over the study period. Comparing the RCA values in 1980, Iran, Israel, Pakistan, Tunisia, and the United Arab Emirates could improve their comparative advantage in date exports later. Conversely, the RCA values in Iraq and Saudi Arabia decreased in 2019compared to 1980 , but they still do enjoy a comparative advantage $(\mathrm{RCA}>1)$.

Table 3. RCA with respect to total exports of agricultural products

\begin{tabular}{lrrrrr}
\hline Country & $\mathbf{1 9 8 0}$ & \multicolumn{1}{c}{$\mathbf{1 9 9 0}$} & \multicolumn{1}{c}{$\mathbf{2 0 0 0}$} & $\mathbf{2 0 1 0}$ & \multicolumn{1}{c}{$\mathbf{2 0 1 9}$} \\
\hline Iran & 2.18 & 45.07 & 40.85 & 34.67 & 20.92 \\
Iraq & 1436.35 & 848.16 & 1567.56 & 1257.24 & 647.33 \\
Israel & 5.76 & 12.20 & 10.84 & 40.19 & 73.41 \\
Pakistan & 0.24 & 22.92 & 45.30 & 19.75 & 11.52 \\
Saudi Arabia & 80.23 & 52.87 & 62.79 & 36.47 & 49.67 \\
Tunisia & 150.09 & 248.32 & 146.78 & 241.13 & 134.91 \\
United Arab & 6.37 & 31.65 & 119.09 & 11.42 & 12.07 \\
Emirates & & & & & \\
Source: calculated by author. & & &
\end{tabular}

Competitiveness of Saudi Date Exports in the World Market: Table 4 shows the competitiveness of Saudi date exports compared to similar exports from competitors in the world market between 1980 and 2019. Saudi Arabia holds a dominant position over four countries (Iran, Israel, Pakistan, and the United Arab Emirates), of the six countries that represented the top exporters of dates in the world during most of the study period. This suggests that Saudi date exports have the ability to gain a large market share in the global agricultural products market relative to its competitors, except Iraq and Tunisia. Saudi Arabia lost some of its dominance in the date export market to other rival countries such as Israel (2010 and 2019), according to the RCA in Table 4. In 
addition, the RCA index decreased for two other countries, Pakistan and the United Arab Emirates. Therefore, we can conclude that the competitive position of Saudi dates in the world market has waned over time.

Table 5 shows the results of the RCA for Saudi dates when compared to other countries at the subdivision level of the world market for date exports. It investigates five markets: Africa, America, Asia, Europe, and the OIC. In 2019, Saudi dates had a relative advantage over dates originating from Iran, Israel, Pakistan, and the United Arab Emirates in the African and OIC markets, while it had a relative disadvantage over dates from Tunisia. Additionally, there was a relative advantage for Saudi dates in the American market during the same period compared to other exporters, except Israel and Tunisia, which have competitive advantage over Saudi. In Asia, Saudi dates held a dominant position in 2019compared to dates exported from other countries, except Iran. In contrast, dates from Saudi Arabia in the European market during 2019hada relative disadvantage compared to dates from most competitors (Iran, Israel, and Tunisia), while in the United Arab Emirates and Pakistan, Saudi dates have the relative advantage. It is evident that there are different competitive positions in different markets for Saudi dates and that itis never in a dominant position in any market. The competitiveness of Saudi dates in 2019, compared to 2007, has seen some change in these different markets (Table 5). In general, there was an improvement in the comparative advantage in African markets over all competitors, while the index of RCA did not have a fixed pattern in other markets. In addition, the results in Table 5 do not show a definite trend in terms of the comparative advantage or disadvantage of Saudi dates relative to any other country across all subdivisions of the market. Also, show that Saudi dates moved from a relative comparative disadvantage in 2007 to an advantageous position in 2019, compared with the United Arab Emirates in the African market and Iran and Pakistan in the American market, while it was vice versa with Iranian the Asia market.

Table 4. RCA for Saudi Arabia with rival countries in world markets in 1980-2019

\begin{tabular}{|c|c|c|c|c|c|}
\hline Country & 1980 & 1990 & 2000 & 2010 & 2019 \\
\hline Iran & 36.74 & 1.17 & 1.54 & 1.05 & 2.37 \\
\hline Iraq & 0.06 & 0.06 & 0.04 & 0.03 & 0.08 \\
\hline Israel & 13.93 & 4.33 & 5.79 & 0.91 & 0.68 \\
\hline Pakistan & 335.79 & 2.31 & 1.39 & 1.85 & 4.31 \\
\hline Tunisia & 0.53 & 0.21 & 0.43 & 0.15 & 0.37 \\
\hline United Arab & 12.60 & 1.67 & 0.53 & 3.19 & 4.11 \\
\hline
\end{tabular}

Emirates

Source: calculated by author.

Table 5. RCA for Saudi Arabia with rival countries in different markets in 2007 and 2019

\begin{tabular}{lrrrrrrrrrr}
\hline Saudi Arabia==> & \multicolumn{2}{c}{ Africa } & \multicolumn{2}{c}{ America } & \multicolumn{2}{c}{ Asia } & \multicolumn{2}{c}{ Europe } & \multicolumn{2}{c}{ OIC } \\
\cline { 2 - 10 } & $\mathbf{2 0 0 7}$ & $\mathbf{2 0 1 9}$ & $\mathbf{2 0 0 7}$ & $\mathbf{2 0 1 9}$ & $\mathbf{2 0 0 7}$ & $\mathbf{2 0 1 9}$ & $\mathbf{2 0 0 7}$ & $\mathbf{2 0 1 9}$ & $\mathbf{2 0 0 7}$ & $\mathbf{2 0 1 9}$ \\
\hline Iran & 17.46 & 83.48 & 0.4 & 1.77 & 1.09 & 0.74 & 0.11 & 0.33 & 1.22 & 1.07 \\
Iraq & 0.01 & NA & 3.89 & NA & 0.03 & NA & 0.30 & NA & 0.02 & NA \\
Israel & 12.54 & 114.41 & 0.46 & 0.25 & 24.11 & 7.14 & 0.05 & 0.04 & 68.27 & 12.15 \\
Pakistan & 8.70 & 69.17 & 0.35 & 1.39 & 2.01 & 4.43 & 1.35 & 1.35 & 49.69 & 10.31 \\
Tunisia & 0.07 & 0.17 & 0.13 & 0.09 & 9.07 & 1.64 & 0.01 & 0.04 & 0.57 & 0.73 \\
United Arab Emirates & 0.69 & 1.66 & 24.73 & 8.96 & 1.10 & 5.03 & 9.60 & 13.4 & 20.67 & 16.49 \\
\hline
\end{tabular}

Source: calculated by author; NA: data is not available.

Table 6. Statistical Estimation of the Partial Adjustment Model for Saudi Dates Exports in 1971 - 2019

\begin{tabular}{l|cccc}
\hline Time Range & $\boldsymbol{D} . \boldsymbol{W}$ & $\boldsymbol{F}$ & $\overline{\boldsymbol{R}}^{2}$ & Equation \\
\hline Short term & 1.99 & 127.3 & 0.91 & $\operatorname{Ln} \hat{\mathrm{Y}}_{t}=-5.86+0.27 \operatorname{Ln} Y_{t-1}+10.05 \operatorname{Ln} X_{1 t}-9.14 \operatorname{Ln} X_{2 t}+0.18 \operatorname{Ln} X_{4 t}$ \\
& & & & $(-2.76)^{* *}(2.57)^{* *}(6.76)^{* *}(-6.29)^{* *}(-1.96)^{*}$ \\
Long term & & & & $\operatorname{LnY} \hat{\mathrm{Y}}_{t}=-8.03+13.77 \operatorname{Ln} X_{1 t}-12.52 \operatorname{Ln} X_{2 t}+0.25 \operatorname{Ln} X_{4 t}$ \\
\hline
\end{tabular}

**The coefficient is significant at $1 \%$ significance level; * The coefficient is significant at $5 \%$ significance level

Table 7. The General Trend Equations to Consider the Characteristics of Dates Exports During the Period 19712019.

\begin{tabular}{|c|c|c|c|}
\hline Variable & $\mathbf{F}$ & $R^{2}$ & Equation \\
\hline Domestic production of dates & 659.83 & 0.93 & $\begin{array}{l}\operatorname{Ln} X_{1 t}=12.45+0.034 T \\
\quad(325.21)^{* *}(25.68)^{* *}\end{array}$ \\
\hline Domestic consumption of dates & 458.93 & 0.91 & $\begin{array}{l}\operatorname{LnX} X_{2 t}=12.44+0.032 T \\
\quad(285.97)^{* *}(21.42)^{* *}\end{array}$ \\
\hline Comparative Advantage of Dates Exports & 111.37 & 0.70 & $\begin{array}{l}\operatorname{Ln} X_{4 t}=5.25-0.038 T \\
\quad(49.52)^{* *}(-10.55)^{* *}\end{array}$ \\
\hline
\end{tabular}

**The coefficient is significant at 5\% significance level; Source: calculated by author. 
Table 8. Measure the Accuracy of the Partial Adjustment Model and Time-Series Equations for the Variables that Determine the Quantity of Saudi Exports of Dates in 1971 - 2019

\begin{tabular}{l|cccc}
\hline Indicators & $\begin{array}{c}\text { Short-run of } \\
\text { partial adjustment } \\
\text { model }\end{array}$ & $\begin{array}{c}\text { Domestic } \\
\text { production of dates }\end{array}$ & $\begin{array}{c}\text { Consumption } \\
\text { of dates }\end{array}$ & $\begin{array}{c}\text { Comparative advantage } \\
\text { of dates exports }\end{array}$ \\
\hline Root Mean Squared Error & 0.256 & 0.130 & 0.148 & 0.361 \\
Mean Absolute Error & 0.172 & 0.084 & 0.094 & 0.286 \\
Mean Abs. Percent Error & 1.710 & 0.641 & 0.719 & 6.829 \\
Theil Inequality Coefficient & 0.012 & 0.004 & 0.005 & 0.041 \\
\hline
\end{tabular}

Table 9. Predictive values of Domestic Production of Dates, Comparative Advantage Index, and Saudi Exports Quantity of Dates in 2019-2025

\begin{tabular}{l|cccc}
\hline Year & $\begin{array}{c}\text { Domestic Production } \\
\text { Quantity of Dates / ton }\end{array}$ & $\begin{array}{c}\text { Domestic Consumption } \\
\text { Quantity of Dates / ton }\end{array}$ & $\begin{array}{c}\text { Comparative Advantage of Saudi Exports Quantity } \\
\text { Dates Exports }\end{array}$ & \begin{tabular}{c} 
Sf Dates / ton \\
\hline
\end{tabular} \\
\hline 2021 & 1495543 & 1334410 & 26.42 & 160858.4 \\
2022 & 1547266 & 1377802 & 25.43 & 170470.9 \\
2023 & 1600777 & 1422605 & 24.48 & 180657.8 \\
2024 & 1656140 & 1468864 & 23.57 & 191453.5 \\
2025 & 1713417 & 1516628 & 22.69 & 202894.2 \\
Mean & 1602629 & 1424062 & 24.52 & 181266.9 \\
\hline
\end{tabular}

Measuring the impact of comparative advantage on future volumes of Saudi exports of dates: According to the analysis, the short-term logarithmic model is the best fit, which is converted to the long-term model using the adjustment coefficient, as shown in Table 6.

The results of the estimated parameters for the econometric model in Table 6 show the following:

1. The estimated value of $(1-\lambda)$ in the short-term econometric model is 0.27 , and the adjustment coefficient $(\lambda)$ value is 0.73 . The $\lambda$ used to convert the model from the short run to the long run. This means that about $73 \%$ of the imbalance in the equilibrium status between the actual and equilibrium level is corrected within one year.

2. The variables of the domestic production, consumption of dates and the relative advantage of date exports are among the most important factors determining the volumes of Saudi date exports in the long term, as it was found that a change of $10 \%$ in both domestic production and the comparative advantage of date exports leads to a change in the same direction of the targeted volume of date exports by $13.7 \%$ and $0.25 \%$, respectively. Whereas, increasing the domestic consumption of dates by $10 \%$ would lead to a decrease in the quantity of Saudi exports of dates by $12.5 \%$.

3. The estimated model has good efficiency in the representation of the data used in the estimation according to the indicators in Table 8 , the most important of which is value of the Theil inequality coefficient, which is close to zero.

To predict the volume of Saudi date exports in 2025, the domestic production, consumption of dates and the relative advantage of Saudi date exports are estimated based on the time-series model (Table 7), which have an accuracy forecast, according to the indicators in Table 8. One of these indicators is the Theil inequality coefficient (U-Theil) value, which is close to 0 . According to forecast values of domestic production of dates in Table 9, the production amount is expected to increase from 1,495,543 tons in 2021 to approximately $1,713,417$ tons in 2025 , with an annual average of 1,602,628.6 tons during the period 2021-2025. the consumption amount is expected to increase from $1,334,410$ tons in 2021 to approximately $1,516,628$ tons in 2025 , with an annual average of $1,424,061.8$ tons during the period 2021-2025. The relative advantage index for Saudi date exports is expected to decrease from 26.42 in 2021 to 22.69 in 2025. Given these predictive values, the volume of longterm Saudi exports for dates is expected to increase from $160,858.4$ tons in 2021 to approximately 202.894 .2 tons in 2025.

Conclusion: The global production of dates is increasing in line with domestic growth in Saudi Arabia, which needs to consider its competitive position relative to other countries in various world markets. Therefore, the study investigated the competitiveness of the date-export market through a market share analysis and the RCA index, across the world market, and the Africa, America, Asia, Europe, and the OIC markets, in 2019, and compared it with the previous period. The study showed that the top competitors for Saudi dates are Iran, Iraq, Israel, Pakistan, Tunisia, and the United Arab Emirates. While Saudi Arabia is one of the top countries in the world for date production, exporting a part of its production, there are some competitors in the date-export market that do not 
have high production volumes, such as Israel and Tunisia. The market shares of Saudi date exports increased during the study period (1980-2019) although there was some fluctuation.

The results of the RCA analysis showed that Saudi Arabia and all major countries that exported dates in 2019hada comparative advantage in date exports over the export of other agricultural products through most of the study period, which means that there is high competitiveness in date exports in the world market. The RCA index values for the export of dates with respect to the export of all agricultural products to the world markets decreased over time even though there was an increase in date export values, which might be owing to an increase in the export value of other agricultural products. The value of the RCA indices of Saudi's dates in the world market compared to dates from other competitors has reversed over time-from a situation in which Saudi Arabia had a comparative advantage over four other exporting countries (Iran, Israel, Pakistan, and the United Arab Emirates) in 1980, 1990, and 2000, to one in which it had a comparative advantage over only Iran, Pakistan, and the United Arab Emirates in 2010 and 2019.In the subdivision markets, Saudi Arabia had a comparative advantage over four countries from six of the top exporters in three markets(Africa, Asia, and the OIC), while the competitiveness of Saudi dates is low in the American and European markets. This may be due to the proportion of Muslims in these markets. Saudi dates were never in a dominant position in any of these markets. The results also showed the reversal of comparative advantage over time for Saudi dates in all markets compared to others. The statistical estimation of Saudi date exports using a partial adjustment model reveals that the most important factors that determine the volume of Saudi dates exports in the long term are domestic production and the comparative advantage of Saudi dates. The study results expect a decrease in the competitiveness of Saudi dates in the world market, in which the relative advantage index over time is expected to decrease by around three and half points in 2025 (32) compared to 2019 (35.5).

Recommendation: The study highlights the high level of competition Saudi dates face in the global market. The research considered several countries characterized by a high level of date consumption, including countries of the OIC. There is some loss of points in the RCA indices with rival countries for dates export of Saudi Arabia in different markets. Therefore, it is important to improve the competitiveness of Saudi dates in the global market. As the production surplus from domestic consumption reached 73 thousand tons. Consequently, agricultural policies that support date exports must be activated to benefit from this surplus. In addition, this research found that Saudi Arabia has a comparative advantage in dates. The markets could be differentiated based on their preference for date varieties, quality requirement and ability to pay, which are linked to the prices. Therefore, the present study recommends further analysis of the characteristics of all markets at the country level to increase dates exports to markets with a higher value in order to increase the returns.

The limitation of this paper is using aggregated data to determine the competitiveness of Saudi dates in the global market. Competitiveness is affected by many factors including for example, dates types in which some types are highly preferred abroad than others, quality standards such as pesticide residues standards, and bilateral and multilateral trade agreements. Hence, future studies should incorporate detailed data to better understand how the Saudi exporters could compete with other elsewhere.

Acknowledgment: The authors would like to extend their gratitude to the Deanship of Scientific Research at King Saud University for funding this work through research group no. RG-1441-388.

\section{REFERENCES}

Ahmed, R. A., M.A. El-Shehawy and L. Lutang. 2011. The structure and competitiveness of China's apple exports. World J. Agric. Res. 7:678-683.

Akhtar, W., M. Sharif, and H. Shah. 2009. Competitiveness of Pakistani Fruits in the World Market. Lahore Journal of Economics. 14:125-133.

Balassa, B. 1965. Trade liberalisation and "revealed" comparative advantage. The Manchester School. 33:99123.

Benkovskis, K. and J. Wörz. 2018. What drives the market share changes? Price versus non-price factors. Structural Change and Economic Dynamics.45:9-29.

Brasili, A., P. Epifani and R. Helg. 2000. On the dynamics of trade patterns. De economist. 148:233-258.

Faostat. 2021. FAOSTAT database. Accessed February 2019. http://www.fao.org/faostat.

Greene, W.H. 2003. Econometric Analysis, Fifth edition. New York University.

Han, X., Y. Wen and S. Kant. 2009. The global competitiveness of the Chinese wooden furniture industry. Forest Policy Econ. 11:561-569.

Helmy, O. 2010. Competitiveness of Egypt in the EU Market for Fruits and Vegetables. Egyptian Center for Economic Studies.

International Trade Centre.2021. International trade statistics 2001-2021. Accessed February 2019. http://www.intracen.org.

Kousar, R., T. Sadaf, , M. S. A. Makhdum, M. A. Iqbal and R. Ullah. 2019. Competitiveness of Pakistan's selected fruits in the world market. Sarh. J. Agric. 35:1175-1184.

Rifin, A. 2013. Competitiveness of Indonesia's cocoa beans export in the world market. Int. J. Trade, Econ. Finance. 4:279-281. 
Rizwan-ul-Hassan, M. 2013. An analysis of competitiveness of Pakistan's agricultural export commodities. IOSR J. Bus. Manag. 11:29-34.

Suntharalingam, C., T. Ahmad, A.K. Ali, R. Rusli and N.A. Halim. 2011. Competitiveness of Malaysia's fruits in the global agricultural and selected export markets: Analyses of revealed comparative advantage (RCA) and comparative export performance (CEP). Econ. Technol. Manag. Rev. 6:1-17.

Torayeh, N.M. 2013. The competitiveness of the Egyptian agricultural export in the EU market: Should Egypt diversify its trade pattern? Appl. Econometrics Int. Dev. 13:129-148. 